\title{
ERRATUM
}

\section{Erratum to: Apparent PS II absorption cross-section and estimation of mean PAR in optically thin and dense suspensions of Chlorella}

\author{
Christof Klughammer • Ulrich Schreiber
}

Published online: 16 October 2014

(C) Springer Science+Business Media Dordrecht 2014

\section{Erratum to: Photosynth Res}

\section{DOI 10.1007/s11120-014-0040-6}

The following errors crept in during the production of the original publication:

The first term in Eq. 17 should read $<\sigma>$ (instead of $\sigma$ ), and the first term in Eq. 18 should read $\sigma$ (instead of $<\sigma>$ ), as follows:

$$
\begin{aligned}
& \begin{aligned}
<\sigma> & =\sigma \cdot \frac{1}{2} \cdot \frac{1-\left(\frac{I_{d}}{I_{0}}\right)^{2}}{1-\frac{I_{d}}{I_{0}}}=\sigma \cdot \frac{1}{2} \cdot \frac{\left(1+\frac{I_{d}}{I_{0}}\right) \cdot\left(1-\frac{I_{d}}{I_{0}}\right)}{1-\frac{I_{d}}{I_{0}}} \\
& =\frac{\sigma}{2} \cdot\left(1+\frac{I_{d}}{I_{0}}\right)
\end{aligned} \\
& \sigma=C \cdot<\sigma>=\frac{2}{1+\frac{I_{d}}{I_{0}}} \cdot\langle\sigma> \\
& C=\frac{2}{1+\frac{I_{d}}{I_{0}}}
\end{aligned}
$$

The online version of the original article can be found under doi:10.1007/s11120-014-0040-6.

C. Klughammer · U. Schreiber $(\bowtie)$

Julius-von-Sachs Institut für Biowissenschaften, Universität Würzburg, Julius-von-Sachs Platz 2, 97082 Würzburg, Germany

e-mail: ulrichschreiber@gmx.de 